\title{
Tensile response of Ultra High Performance PE Fiber Reinforced Concretes (PE-UHPFRC) under imposed shrinkage deformations
}

\author{
A. Hajiesmaeili (i) - M. A. Hafiz • E. Denarié
}

Received: 7 November 2019/Accepted: 31 December 2020/Published online: 6 May 2021

(C) The Author(s) 2021

\begin{abstract}
PE-UHPFRC is a new Ultra High-Performance Fiber Reinforced Concrete (UHPFRC), which is developed to reduce the environmental impact of conventional UHPFRC by replacing the steel fibers with synthetic ones and reducing the clinker content in the mix. The development of the dynamic elastic modulus, the evolution of free autogenous deformations and the eigenstresses development with age, under full and partial restraint conditions, were investigated for PE-UHPFRC and the results were put into perspective with that for conventional UHPFRC with steel fibers. Furthermore, the tensile responses of different mixes under imposed shrinkage were compared and discussed. The results showed a shorter setting time and consequently an earlier initiation of elastic modulus development for PEUHPFRC compared with that of conventional UHPFRC. Furthermore, the developed eigenstresses under full restraint conditions in a PE-UHPFRC layer compared with that for conventional UHPFRC were reduced by more than $70 \%$, which is highly beneficial especially for cast-in-place rehabilitation applications.
\end{abstract}

A. Hajiesmaeili $(\bowtie) \cdot$ M. A. Hafiz · E. Denarié

Maintenance and Safety of Structures, Ecole

Polytechnique Fédérale de Lausanne, Station 18, GC A3

398, 1015 Lausanne, Switzerland

e-mail: Amir.Hajiesmaeili@epfl.ch
Keywords UHPFRC $\cdot$ UHMW-PE · PE-UHPFRC · Autogenous shrinkage $\cdot$ Eigenstresses $\cdot$ TSTM . Tensile response

\section{Introduction}

The aging of transportation infrastructures together with the increasing demand of the society have intensified the need for effective and sustainable structural rehabilitation and strengthening techniques. In this regard, the concept of rehabilitation and strengthening of existing bridges with UHPFRC, using a thin UHPFRC overlay in zones of severe mechanical and environmental exposure, has gained the ground over the past decades [1].

Composite UHPFRC-Concrete members are subjected to internal deformations and to external actions. The internal autogenous deformations are mainly due to chemical shrinkage, self-desiccation after setting, drying shrinkage (more or less pronounced depending on UHPFRC recipes) and thermal effects caused by the heat of hydration in the new layer. These deformations starting at early age are restrained by the existing structure as well as the reinforcement bars, if any, in the UHPFRC layer [2]. The very high degree of restraint (load level of the overlay with respect to that for full restraint) of cast-in-place applications with thin overlays (often close to 90\%) [3] leads to the 
development of pronounced tensile eigenstresses in the UHPFRC layer [4-7] which constitute a net loss of the performance in terms of potential tensile capacity.

Several authors reported results on the effect of restrained shrinkage for UHPFRC mixes with steel fibers. Schachinger et al. [8, 9] investigated the cracking risk of two types of UHPC with CEM I $42.5 \mathrm{R} / \mathrm{HS}$ and CEM III B $42.5 \mathrm{NW} / \mathrm{HS}$ (HS: resistant to sulfates, NW: low heat of hydration), due to restrained autogenous deformation until 28 days, and reported that a cracking risk exists within the first $15 \mathrm{~h}$ for the mixes with CEM I 42.5 R/HS. Habel et al. [6] studied the evolution of autogenous deformations and their associated eigenstresses in UHPFRC under incremental restraint, at $20^{\circ} \mathrm{C}$. The comparison of the developed eigenstresses and tensile properties of UHPFRC until 7 days showed that the cracking risk is higher during the first two days. The study of Kamen et al. [4] on the thermo-mechanical response of UHPFRC at early age showed that even though increasing the curing temperature from 20 to $30{ }^{\circ} \mathrm{C}$ prepones the initiation of eigenstresses development, it has a negligible effect on the eigenstresses at 7 days and no evidence of damage was observed. Yoo et al. [10] studied the effect of the restraint ratio on the cracking behavior of UHPFRC until 7 days by conducting restrained ring-tests with different ring thicknesses, in which the specimen with thicker steel rings (corresponding to a higher degree of restraint) demonstrated a faster cracking time than the ones with thinner steel rings. The influence of the degree of restraint on the cracking risk was confirmed by [11] who investigated the effect of specimen thickness on restrained shrinkage and cracking behaviors of thin UHPFRC slabs until 9 days. The authors studied two different thicknesses of 35 and $45 \mathrm{~mm}$ for the UHPFRC layer and showed that the degree of restraint and the cracking risk were reduced as the thickness of the specimen increased. Furthermore, Weimann et al. [12] reported multiple cracks with crack widths smaller than $50 \mu \mathrm{m}$ in Engineered Cementitious Composites (ECC), in a ring test subjected to approximately $90 \%$ restrained shrinkage, due to the relatively low tensile elastic limit of this material.

Even though it was shown that the cracking risk is higher at an early age for UHPFRC mixes, it should also be considered that eigenstresses continue to increase with age as a consequence of the autogenous shrinkage, and they may reach the Strain hardening domain at a later age. However, only a few notable studies investigated the eigenstresses development in UHPFRC beyond 28 days. Hafiz et al. [13] studied the development of eigenstresses in UHPFRC under full restraint conditions and showed that these stresses could reach values higher than the elastic limit and even reach the tensile strain hardening domain of the material after one month at $20{ }^{\circ} \mathrm{C}$ curing.

PE-UHPFRC is a UHPFRC mix in which 50 vol\% of the clinker is replaced with limestone fillers [14] and the steel fibers are replaced with Ultra High Molecular Weight Polyethylene (UHMW-PE) ones. This newly developed mix has equivalent or better properties (tensile strain hardening) than mixes realized with steel fibers, adapted for cast-in-place applications of reinforcement of existing structures (sort UA after [15]). Furthermore, it has the potential to reduce the eigenstresses in UHPFRC by reducing the autogenous shrinkage and increasing the viscoelastic response of the material. Kang et al. [16] showed that autogenous shrinkage decreases proportionally with the increase in limestone filler content. The autogenous shrinkage decreased by more than $30 \%$ by replacing $50 \%$ mass of cement with limestone filler. Furthermore, Hafiz et al. [13] reported a higher viscoelastic response for a mix with $50 \%$ mass replacement of clinker with limestone filler. Additionally, Bissonnette et al. [17] found higher tensile creep for a concrete mix with smaller diameter steel fibers due to the influence of the fibers on the microstructure of the paste at the paste fiber interface. Therefore, the much smaller diameter of the PE fibers $(0.012 \mathrm{~mm})$ compared with that of steel fibers ( 0.16 to $0.2 \mathrm{~mm}$ ) can have a potential to increase the tensile creep of PE-UHPFRC, and consequently reduce the eigenstresses by providing greater stress relaxation compared to the mixes with steel fibers.

The present study reports on the delayed response under imposed shrinkage deformations of PEUHPFRC compared with that of conventional UHPFRC. In a first step, the investigated materials and their properties are presented. Secondly, the methods are described, highlighting the use of a Temperature Stress Testing Machine (TSTM) to investigate the eigenstresses development under full restraint conditions, and the Vibration Resonance Frequency test (VRF) to study the development of the dynamic elastic modulus with age. The development of the elastic modulus, the evolution of autogenous 
deformations, and the development of eigenstresses are investigated for three types of UHPFRC mixes including (1) PE-UHPFRC with PE fiber and 50 vol\% replacement of clinker with limestone filler, (2) S-UHPFRC with steel fibers, and (3) S-LF-UHPFRC with steel fibers and 50\% mass replacement of clinker with limestone filler. Finally, the tensile responses of different UHPFRC mixes under imposed shrinkage deformations are put into perspective and the effect of the viscoelastic response on reducing the apparent elastic modulus of different mixes at very low loading rates is discussed.

\section{Materials}

Four mixes were used: (1) a newly developed UHPFRC mix, named PE-UHPFRC, in which the steel fibers were fully replaced by UHMW-PE ones and $50 \%$ volume of the clinker was replaced by limestone fillers [18], (2) a conventional UHPFRC mix with steel fibers from the $\mathrm{CEMTEC}_{\text {multiscale }}{ }^{(}$ family [19], optimized and modified at MCS/EPFL [20, 21], designated as S-UHPFRC, (3) a UHPFRC mix based on S-UHPFRC in which $50 \%$ of the cement was replaced with inert limestone filler henceforth referred to as S-LF-UHPFRC [13], and (4) a mix similar to that of PE-UHPFRC with less sand and without quartz powder, named PE-UHPFRC(*). Six different powders including cement CEM I 52.5 HTS Lafarge, two types of limestone fillers of different gradings: Betoflow $\mathrm{D} \AA$ and Betocarb SL $\AA$ (OMYA), white silica fume from SEPR $\left(\right.$ BET $=14 \mathrm{~m}^{2} / \mathrm{g}$ ), quartz powder $\left(d_{50}=11.4 \mu \mathrm{m}\right)$ and fine quartz sand $\left(d_{50}=250 \mu \mathrm{m}\right)$ were used in the mixes. The detailed compositions of the mixes are given in Table 1.

The PE-UHPFRC and PE-UHPFRC $(*)$ have a fibrous mix containing 2 vol\% UHMW-PE fiber $\left(l_{\mathrm{f}}=6 \mathrm{~mm}, d_{\mathrm{f}}=0.012 \mathrm{~mm}\right)$ type SK99 ( $E$ modulus $=155 \mathrm{GPa})$ and SK $62(E$ modulus $=86 \mathrm{GPa})$, respectively. The fibrous mix of both S-UHPFRC and S-LF-UHPFRC consisted of two types of micro (with a semi-circular section with variable dimensions) and macro (with $l_{\mathrm{f}}=10 \mathrm{~mm}, d_{\mathrm{f}}=0.2 \mathrm{~mm}$ ) fibers with a total dosage of $9 \mathrm{vol} \%$. It should be noted that due the different geometry of the PE and steel fibers, there are almost 100 times $\left(2 / 9 \times 10 / 6 \times 0.2^{2} / 0.012^{2}\right)$ more individual fibers in PE mixes compared to that of steel fiber mixes, despite a higher fiber volume (9\%) in the latter.

The strain hardening part of the tensile response of the mixes 1, 2, and 3 are illustrated in Fig. 1. Furthermore, the mechanical properties of the same mixes in the hardened state are shown in Table 2. The tensile properties are the average of 15 and 8 uniaxial tensile tests on dumbbell specimens with a thickness of $30 \mathrm{~mm}$, for PE and steel fiber UHPFRC mixes, respectively. The compressive strength is the average of results on three cylinders after [15]. The average compressive strength of mix PE-UHPFRC $(*)$ on three cylinders $7 / 14 \mathrm{~cm}$ after [15] was 119.7 at 28 days.

As shown in Fig. 1, the fiber type highly influences the tensile behavior of UHPFRC mixes, steel fibers lead to higher strength while PE fibers offer higher strain capacity [22]. In addition, it can be seen that replacing $50 \%$ of the clinker with limestone filler slightly reduces both tensile strength and tensile elastic limit in steel fiber UHPFRC mixes.

\section{Experimental procedure}

\subsection{Delayed response}

The free autogenous deformations and eigenstresses development of the UHPFRC mixes under full and partial restraint conditions were investigated using a Temperature Stress Testing Machine [23-25] at MCS/ EPFL [26] from a very early age, directly after casting. Quasi-isotherm temperature conditions of $20{ }^{\circ} \mathrm{C}$ were ensured in the specimen with the help of a cooling circuit surrounding the molds. The TSTM setup is shown in Fig. 2.

The setup consisted of two parts. The free autogenous deformations were measured with the Free Setup and the eigenstresses development under full and partial restraint conditions were investigated using the Restrained Setup with the help of a load cell and an electromechanical actuator linked to a closed loop control system. The associated free deformations in the restrained specimen, as well as the free deformations in the free system, were determined by means of the measurements of two LVDT in each specimen, attached to a rod inserted in the material immediately after casting, through openings in the molds. In the Restrained Setup, two LVDT (A and B) with a range of $\pm 0.5 \mathrm{~mm}$ were placed $750 \mathrm{~mm}$ apart, whereas in the 
Table 1 Mix proportions of the PE-UHPFRC, PE-UHPFRC(*), S-UHPFRC and S-LF-UHPFRC

\begin{tabular}{lllll}
\hline Components $\left(\mathrm{kg} / \mathrm{m}^{3}\right)$ & $(1)$ PE-UHPFRC & (2) S-UHPFRC & (3) S-LF-UHPFRC & (4) PE-UHPFRC(*) \\
\hline Cement & 508 & 1467 & 733.7 & 627.8 \\
Silica fume & 178 & 381.4 & 293.5 & 220 \\
Betocarb®-HP SL & 170 & - & 223 & 210 \\
Betoflow®-D & 389 & - & 501.6 & 480.6 \\
Fine Sand & 525 & - & - & 348.4 \\
Quartz Powder & 223 & - & - & - \\
Water & 165 & 225.8 & 217.9 & 224 \\
Water/fines & 0.124 & 0.129 & 0.129 & 0.146 \\
Water/cement & 0.357 & 0.163 & 0.310 & 0.357 \\
UHMW-PE fiber & 19.6 & - & - & 19.6 \\
Steel fibers & - & 706.5 & 706.5 & - \\
HRWRA & 27 & 20.5 & 14.7 & 26.4 \\
Ca(NO $\left.{ }_{3}\right)_{2}$ & 11 & - & - & 13.2 \\
Defoaming agent & 0.1 & - & - & 0.1 \\
\hline
\end{tabular}

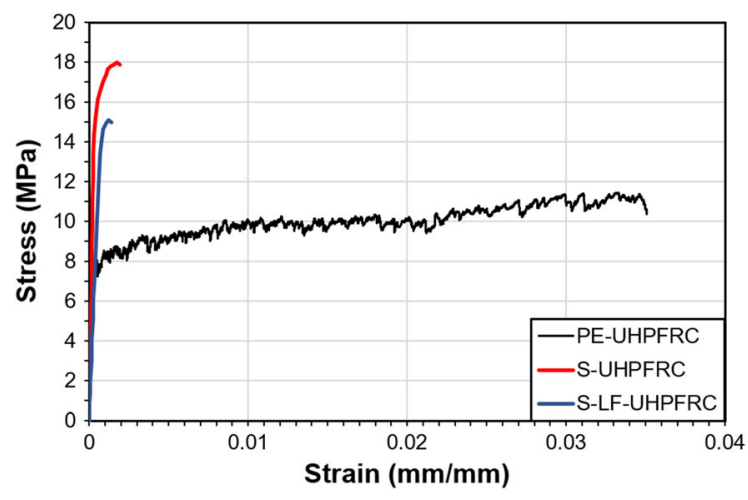

Fig. 1 Tensile response of the PE-, S-, and S-LF- UHPFRC mix (for direct comparison, only the strain hardening response of the three mixes is shown)

Free Setup, two LVDT (C and D) with a range of $\pm 2.5 \mathrm{~mm}$ were installed $750 \mathrm{~mm}$ apart from each other, as shown in Fig. 2. The eigenstresses were calculated by dividing the force measured by the load cell with the cross-sectional area of the specimen. In both devices, fully sealed specimens of cross-sectional dimensions $50 \mathrm{~mm} \times 100 \mathrm{~mm}$ were used. Further details regarding the TSTM setup can be found in [26-29].

The autogenous shrinkage was calculated by dividing the difference of displacements shown by LVDT $\mathrm{C}$ and D by the distance between them, assuming a linear variation of the autogenous deformation from one end to the other in the Free Setup. The partial restraint test was conducted using stroke control, in which the stroke was kept in the same relative position without any movement, throughout the test. The partial restraint imposed by the finite stiffness of the machine in this test was determined by comparing the free deformations in the restrained system and the free deformations in the free system.

Table 2 Mechanical properties of the PE-UHPFRC, S-UHPFRC, and S-LF-UHPFRC, average (standard deviation), at 28 days

\begin{tabular}{lccc}
\hline Properties & PE-UHPFRC & S-UHPFRC & S-LF-UHPFRC \\
\hline Tensile strength (MPa) & $11.7(0.6)$ & $18(3.1)$ & $15.1(2.7)$ \\
Tensile elastic limit (MPa) & $7.7(0.5)$ & $12.3(1.7)$ & $11.1(1.9)$ \\
Tensile strain at peak stress (\%) & $35(10)$ & $1.64(0.44)$ & $1.27(0.51)$ \\
Compressive strength (MPa) & $120(2.6)$ & $230.5(0.85)$ & $169.7(0.5)$ \\
Young's modulus $^{\mathrm{a}}(\mathrm{GPa})$ & $42.6(2.2)$ & $51(2.3)$ & $46.3(1.3)$ \\
\hline
\end{tabular}

${ }^{\mathrm{a}}$ After SIA 262/1, Annex G 
(a)

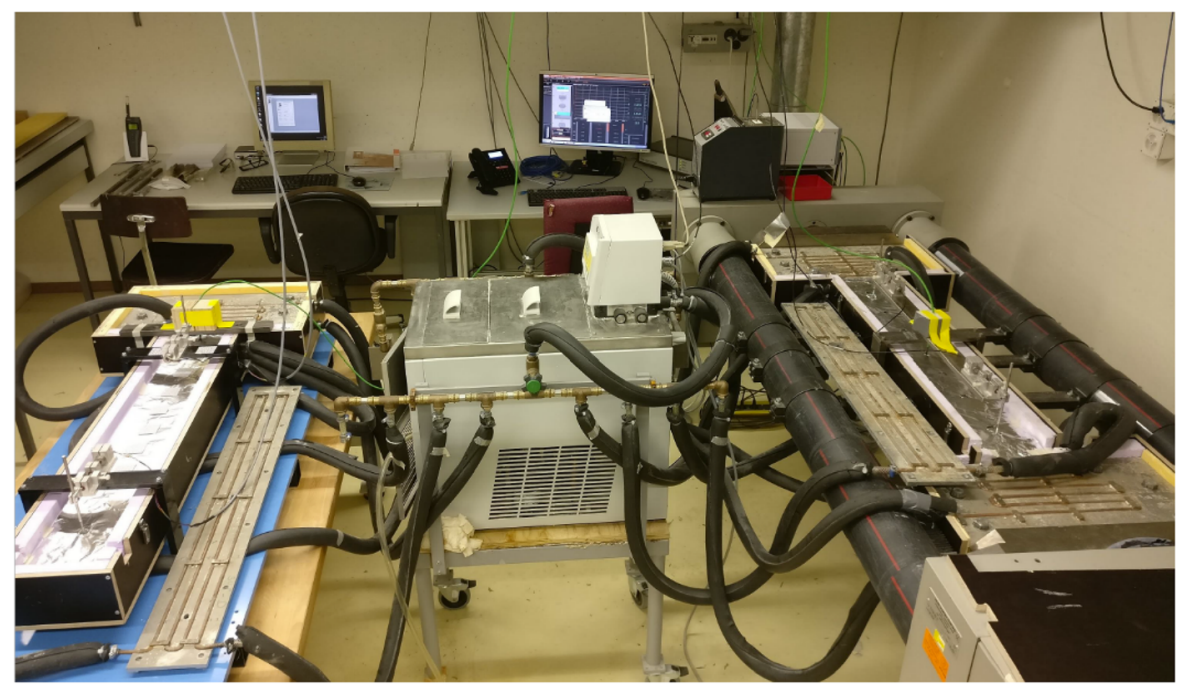

(b)

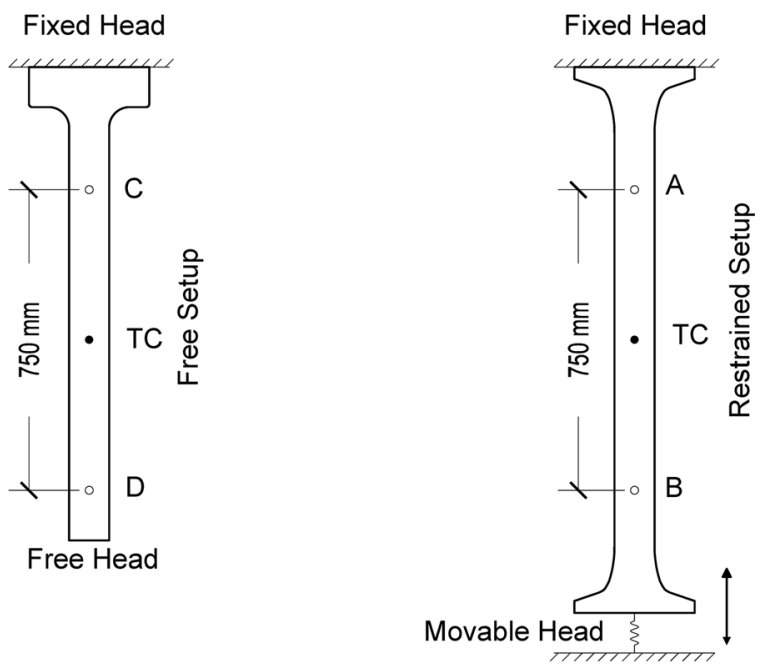

Fig. 2 TSTM setup: a overview with cooling system, b schematic representation of the specimen's geometry and location of measurement points of transducers (A, B, C, D) and thermocouples (TC)

For the full restraint tests, in order to ensure fully restrained condition in the Restrained Setup, the deformations were controlled actively after setting to keep the relative displacement between the two points $\mathrm{A}$ and $\mathrm{B}$ at zero. However, at the fresh state and in the very early age close to setting time, the material stiffness was too low to impose a closed loop force or deformation control. As such, the tests were started under stroke control (passive control) with the stroke remaining in the same position as that at the start of the test. The monitored development of eigenstresses under passive stroke control was used to determine the stress to activate the deformation control leading to full restraint condition. A value of $0.2 \mathrm{MPa}$ in tension (equivalent to $100 \mathrm{~kg}$ acting on the specimen cross section) was chosen as the trigger value, to be low enough to minimize the impacts on the viscous effects of the loading history induced by the passive stroke control timeframe after setting, while being high enough to reach a sufficient stiffness of the specimen to respond to a closed loop deformation control without yielding out of control.

Table 3 gives an overview of all the tests performed using the TSTM set-up. For mixes 1, 2, and 3, two full 
restraint tests were carried out. Additionally, one partial restraint test was carried out on PE$\mathrm{UHPFRC}(*)$.

\subsection{Development of elastic modulus}

The vibration resonance frequency (VRF) test method $[27,30]$ was used to determine the dynamic elastic modulus of the mixes from an early age and assess its development with age. The method is based on the measurement and analysis of natural vibration frequencies of the first two longitudinal modes of vibration of a cylindrical specimen using the Rayleigh-Ritz method, which relates the frequencies of vibration to the elastic modulus and the density of the material for a given geometry. Cylindrical specimens with a diameter of $70 \mathrm{~mm}$ and a length of $140 \mathrm{~mm}$ were used for the tests. The measurements of the frequencies started shortly after setting time of the material. A $10 \mathrm{~mm}$ diameter steel ball suspended with a steel thread was used to hit the center of one of the circular faces of the specimen. The hits were done automatically using an arm connected to a step motor with a magnetic head, once per minute. The propagated longitudinal waves were then captured by a miniature accelerometer at the opposite face of the specimen. The captured waves were digitized and analyzed using signal processing to obtain the 1 st and 2 nd resonance frequency of the specimen. The elastic modulus at different age was calculated using the resonance frequencies of the specimen and the density of the material (Fig. 3). In order to estimate the setting time and start the measurement from the beginning of elastic modulus development, the temperature evolution was monitored in another specimen, using a thermocouple inserted right after casting.

Table 3 Overview of the performed tests with TSTM

\begin{tabular}{lll}
\hline Material & Duration & Restraint condition \\
\hline PE-UHPFRC & 30 days and 65 days & Full \\
S-UHPFRC & 31 days and 65 days & Full \\
S-LF-UHPFRC & 32 days and 65 days & Full \\
PE-UHPFRC $(*)$ & 28 days & Partial $(0.65)$ \\
\hline
\end{tabular}

\section{Results and discussion}

\subsection{Development of elastic modulus}

The development of the dynamic elastic modulus is shown in Fig. 4 on a semi-log scale for the mixes 1, 2 and 3. As expected, the final dynamic elastic modulus of the mix with steel fibers was higher than that for the PE-UHPFRC. The dynamic elastic modulus was slightly higher than the static ones (Table 2) and reached above $51 \mathrm{GPa}$ in S-UHPFRC and S-LFUHPFRC mixes, and $45 \mathrm{GPa}$ in PE-UHPFRC mixes, after 14 days.

The measurements on the S-LF-UHPFRC specimens started at the age of $15 \mathrm{~h}$, when the dynamic elastic modulus had already reached $10 \mathrm{GPa}$. However, from the trend of the curves, it can be seen that the development of the elastic modulus started in S-LF-UHPFRC slightly earlier than in S-UHPFRC, and it started in PE-UHPFRC approximately $10 \mathrm{~h}$ earlier than the other two mixes. The difference between the results for the two steel fiber mixes can be explained considering the difference in their superplasticizer dosage. S-LF-UHPFRC had $14.7 \mathrm{~kg} / \mathrm{m}^{3}$ superplasticizer whereas S-UHPFRC had $20.5 \mathrm{~kg} / \mathrm{m}^{3}$. The retarding effect of the superplasticizer can delay the setting time and consequently the initiation of the elastic modulus development. The considerable difference between the PE-UHPFRC and the other two

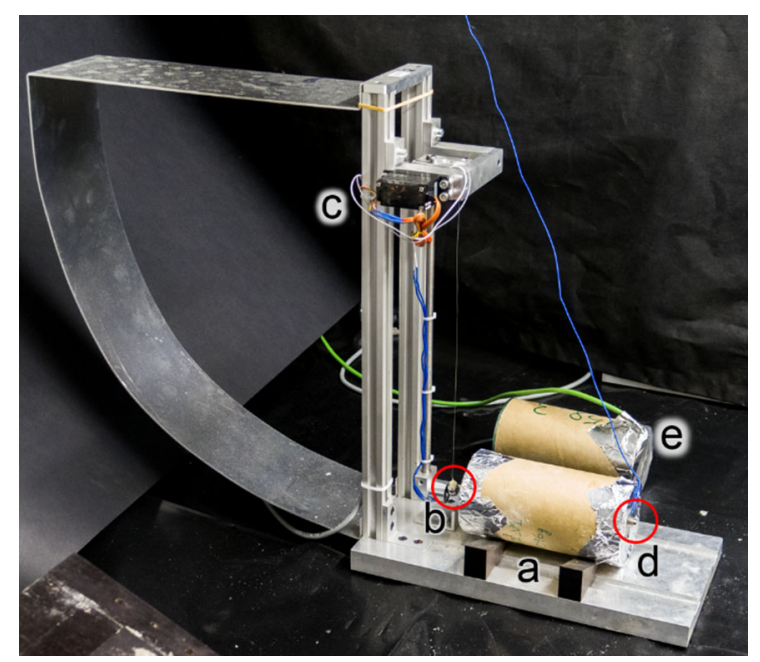

Fig. 3 VRF setup: a cylindrical VRF specimen, b steel ball, c automatic hitting system, $\mathbf{d}$ accelerometer, e specimen for measuring temperature evolution 


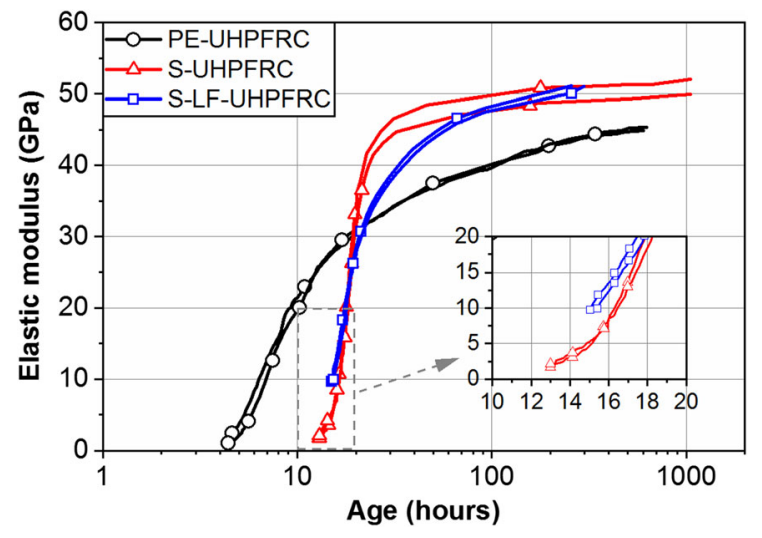

Fig. 4 Development of dynamic elastic modulus for PEUHPFRC, S-UHPFRC, and S-LF-UHPFRC

mixes can be attributed to the accelerating effect of $\mathrm{Ca}\left(\mathrm{NO}_{3}\right)_{2}$ used in the mix with PE fibers. Bost et al. [31] showed a significant accelerating effect of calcium nitrate on Portland cement even at a very low concentration. Thus, the $\mathrm{Ca}\left(\mathrm{NO}_{3}\right)_{2}$ in PE-UHPRC mixes reduced the setting time and accordingly preponed the initiation of elastic modulus development. Additionally, the effect of limestone filler in accelerating the hydration of cement grains by acting as crystallization nucleus [32], and in reducing the interparticle spacing product (at a constant liquid content and for limestone particles finer than cement) [33] played a role in reducing the setting time and therefore bringing forward the initiation of the elastic modulus development in PE-UHPFRC and S-LFUHPFRC. A similar trend was reported in [33-35].

Even though the development of the elastic modulus started earlier in the PE-UHPFRC mix compared with that for the other two mixes, at the age of $20 \mathrm{~h}$ all the mixes reached an elastic modulus of $30 \mathrm{GPa}$ as the result of different development rates. Figure 5 shows the rate of elastic modulus development in UHPFRC mixes 1, 2, and 3. The rate of elastic modulus development had a higher peak in the S-UHPFRC mix compared with the other two mixes which had a similar trend. This can be attributed to the dilution effect of the limestone filler by increasing the water/ cement $(w / c)$ ratio in the mixes. The $w / c$ ratio of the S-UHPFRC was 0.15 while the $w / c$ ratio of PEUHPFRC and S-LF-UHPFRC were 0.32 and 0.30 , respectively. Considering the increase in the rate of drop of relative humidity with a decrease in the $w /$ $c$ ratio [36] and taking into account the similar kinetics

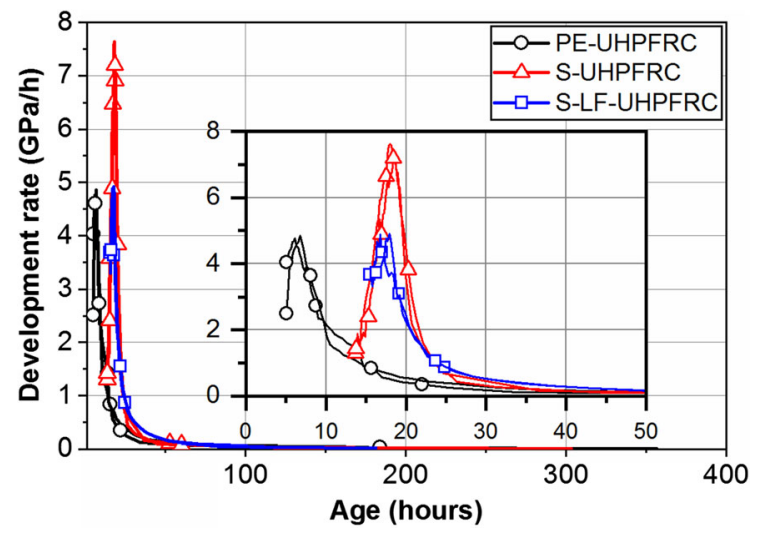

Fig. 5 Rate of elastic modulus development in PE-UHPFRC, S-UHPFRC, and S-LF-UHPFRC

of the rate of hydration and the changes in the relative humidity, the different rates of elastic modulus development of the mixes can be explained. The rate of elastic modulus development approached zero after 14 days.

\subsection{Free autogenous deformations}

The evolution of the free autogenous deformations $\left(\varepsilon_{\text {free }}{ }^{\text {free }}\right)$ of the UHPFRC mixes are presented in Fig. 6. In this figure, the deformations are zeroed at the end of swelling and increasing strains indicate shrinkage. All the mixes showed a fast autogenous shrinkage in the first few days. This trend can be explained by the progress of the hydration process and refinement of the pore structure with fast consumption of water [27].

The results of both full restraint test series on the PE-UHPFRC mix were almost superimposed which showed a very good reproducibility. The PEUHPFRC $(*)$ mix showed a higher shrinkage than that in PE-UHPFRC at an early age until $12 \mathrm{~h}$. The higher autogenous shrinkage of PE-UHPFRC $(*)$ can be explained by a lower sand content in this mix $\left(348.5 \mathrm{~kg} / \mathrm{m}^{3}\right.$ compared with $525 \mathrm{~kg} / \mathrm{m}^{3}$ in PEUHPFRC) and also its higher water/fines ratio. Cheyrezy and Behloul [37] found that below w/b of 0.17 , the autogenous shrinkage decreases with the $\mathrm{w} / \mathrm{b}$ ratio. The autogenous deformations were higher in PEUHPFRC compared to that in UHPFRC mixes with steel fibers. The stiff and very dense steel fibers skeleton in S-UHPFRC and S-LF-UHPFRC resists against the autogenous deformations and reduces the 
(a)

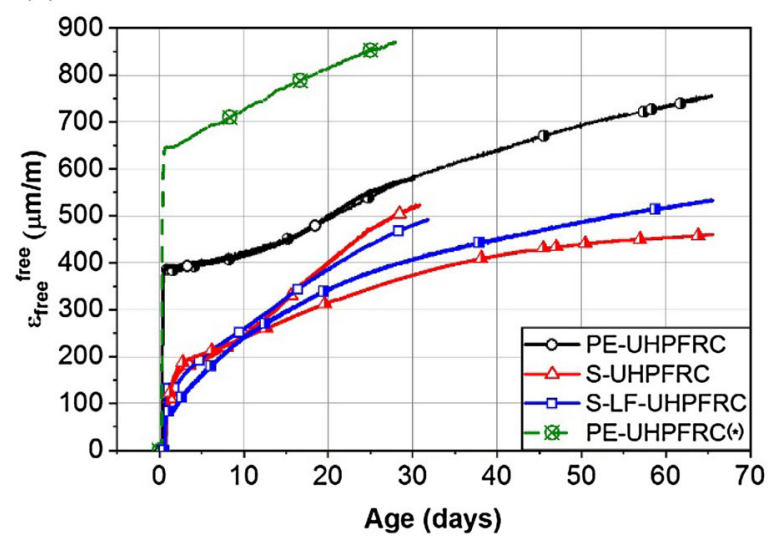

(b)

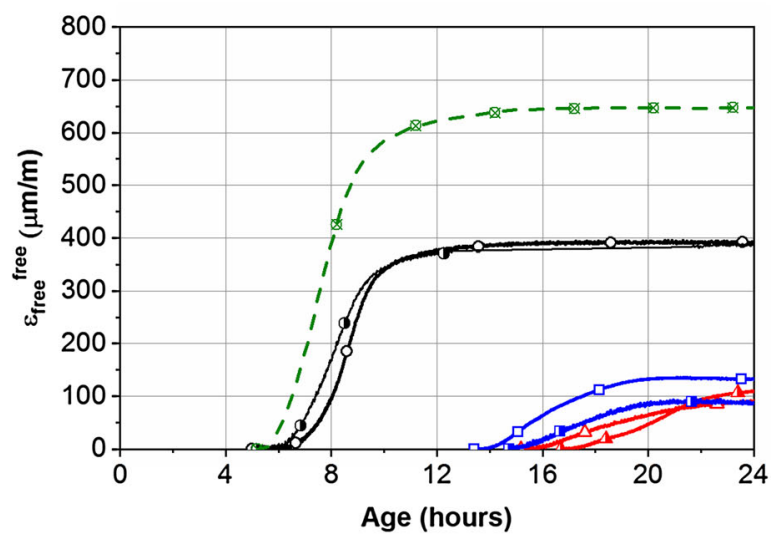

Fig. 6 Evolution of free autogenous deformations of different UHPFRC mixes (a) zoom until $24 \mathrm{~h}$ (b) (increasing strains indicate shrinkage)

autogenous shrinkage at early ages [38-40] while the flexible PE fibers cannot hinder those autogenous deformations. This difference was reduced as the stiffness of the matrix increased with age and the role of the fibers' stiffness in controlling the deformations was lessened. A trend similar to that of PE-UHPFRC mixes was reported for the autogenous deformations of a PVA fiber reinforced Engineered Cementitious Composites (ECC) in [41].

Contrary to the finding of [16] regarding the effect of limestone filler in reducing the autogenous shrinkage in UHPFRC mixes, no considerable difference was observed between the autogenous shrinkage of S-UHPFRC and S-LF-UHPFRC in which $50 \%$ of cement was replaced with limestone filler. This discrepancy can be explained by considering a similar effect as that of the relative volume fraction of the fibrous mix and sand on the yield stress of the fresh mix, which indicates the resistance of a material against deformation, for autogenous shrinkage. Martinie et al. [42] showed that the yield stress of fresh cementitious composites is strongly correlated to the sum of the relative volume fraction of the fibers and the relative volume fraction of the granular skeleton: $\Phi_{\mathrm{f}} /(r / 4)+\Phi_{\mathrm{s}} / \Phi_{\mathrm{m}}$, where $\Phi_{\mathrm{f}}$ is the volume fraction of fibers, $r$ is the aspect ratio of the fiber (length/diameter), and $\Phi_{\mathrm{s}}$ and $\Phi_{\mathrm{m}}$ are the volume fraction and the dense packing fraction of the sand respectively. The investigated mix in [16] had $162 \mathrm{~kg} / \mathrm{m}^{3}$ steel fibers $(13 / 0.2 \mathrm{~mm})$ and $873 \mathrm{~kg} / \mathrm{m}^{3}$ of fine sand while the S-UHPFRC and S-LF-UHPFRC mixes had $471 \mathrm{~kg} / \mathrm{m}^{3}$ steel fibers $(10 / 0.2 \mathrm{~mm})$ and $235.5 \mathrm{~kg} / \mathrm{m}^{3}$ of steel wool that has a similar effect as sand. Considering 0.6 and 0.13 (experimental values) for dense packing fractions of the sand and the steel wool, respectively, the total relative volume fraction of the rigid inclusions is 0.87 and 0.98 for the mix studied in [16] and the UHPFRC mixes with steel fiber in this study, respectively. Thus, similar to the effect of increasing the total relative volume fraction of the rigid inclusions on increasing the yield stress of the fresh mix, it can be assumed that increasing the total relative volume fraction of the rigid inclusions in S-UHPFRC and S-LF-UHPFRC led to increasing the resistance to deformation and reduced the effect of limestone filler on the autogenous shrinkage.

\subsection{Eigenstresses under full/partial restraint}

Figure 7 shows the eigenstresses development of PEUHPFRC, S-UHPFRC, and S-LF-UHPFRC under full restraint and PE-UHPFRC $\left({ }^{*}\right)$ under partial restraint condition. The degree of restraint was 0.65 for the partial restraint test, estimated from the asymptotic ratio after 90 days, of the free deformations in the restrained set-up to the free deformations in the free set-up) per equation $\left(\varepsilon_{\text {restrained }}{ }^{\text {free }} / \varepsilon_{\text {free }}{ }^{\text {free }}\right)$. Even though the autogenous shrinkage of PE-UHPFRC $(*)$ was approximately 1.5 times higher than that for the PE-UHPFRC mix, the eigenstresses development of these two mixes followed a very similar trend and were almost superimposed, despite the very different degrees of restraint. Considering similar viscoelastic responses for the two PE fiber mixes, this can be 


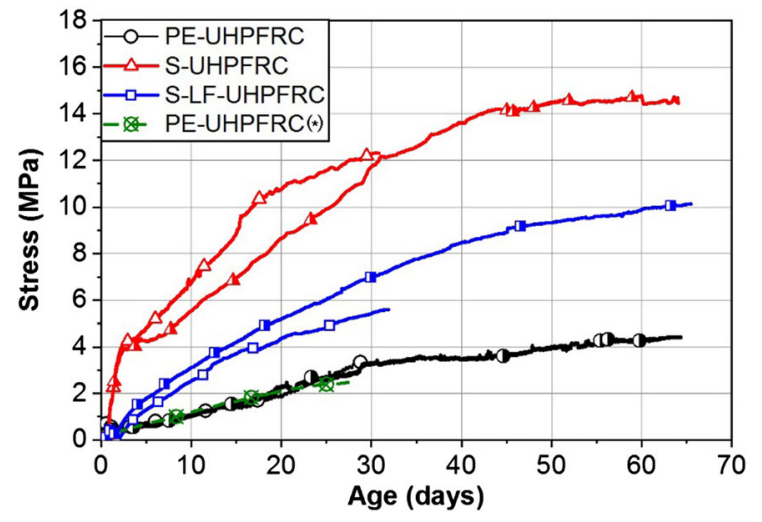

Fig. 7 Eigenstresses development of different UHPFRC mixes, quasi isotherm curing conditions at $20^{\circ} \mathrm{C}$

explained by the opposing effects of a higher shrinkage (almost 1.5 times more for mix 4 ) but of a lower restraint $(0.65)$ also for mix $4(1.5 \times 0 . \approx 1)$.

The value of eigenstresses in a $50 \mathrm{~mm}$ thick layer of PE-UHPFRC at 28 days decreased by a factor of 2 and 4 compared with that for S-LF-UHPFRC and S-UHPFRC, respectively. The lower value of eigenstresses in PE-UHPFRC might be explained in two levels: from a matrix and from a fibrous mix point of view. Regarding the matrix, Hafiz et al. [13] showed a higher viscoelastic response for the mixes with a higher dosage of limestone filler in creep tests starting at 14 days age, which consequently results in a higher relaxation potential and help to mitigate the developed eigenstresses. Concerning the fibrous mix, it was shown that using fibers (steel or synthetic ones) in a cementitious matrix increases creep in tension $[17,43,44]$ especially in the case of fibers with a smaller diameter [17]. Thus, the smaller diameter and higher number of the PE fibers compared to the steel fibers can lead to higher tensile creep in PE-UHPFRC mixes. Furthermore, Garas et al. [45] found a higher tensile creep for the UHPFRC specimens cured at room temperature compared with that for the thermally treated specimens due to the relatively lower stiffness of fiber/matrix interfaces in the former specimens. Accordingly, a higher volume of relatively low-stiffness fiber/matrix interface in PE-UHPFRC mixes due to the higher number of PE fibers compared with steel fibers may lead to a higher tensile creep in these mixes. Consequently, the higher tensile creep capacity of PE-UHPFRC mixes can provide greater stress relaxation compared to the mixes with steel fibers and reduce the developed eigenstresses.

\subsection{Tensile response under imposed shrinkage deformations}

Figure 8 shows the tensile response of the UHPFRC mixes under imposed shrinkage deformations with very low loading rates. For the full restraint specimens, the free autogenous shrinkage deformation from the Free Setup was considered as the deformation acting on the specimen in Restraint Setup and causing the eigenstresses development. In case of the partial restraint specimen, PE-UHPFRC $(*), 65 \%$ of the free autogenous shrinkage deformation from Free Setup, which was the real deformation acting on the specimen according to the degree of restraint, was used for the strain calculations.

All the mixes showed a bilinear tensile response (until the elastic limit) starting with smaller slope and continuing with a higher slope. Viscous effects (relaxation) significantly decrease the impact of the autogenous shrinkage on the development of eigenstresses, especially during the first linear part until point A (orange circles in Fig. 8). Considering the development of dynamic elastic modulus in Fig. 4, the first linear part of the tensile response with a lower slope finished when the dynamic elastic modulus reached $43 \mathrm{GPa}$ in all the mixes. Table 4 shows the age and dynamic elastic modulus of the specimens at point A.

The second slope of the tensile response corresponded to the elastic modulus of the materials at a very low loading rate (that of the shrinkage deformations), which intrinsically includes the effect of relaxation due to the viscoelastic response. The average slopes of the second linear part were $37 \mathrm{GPa}, 22 \mathrm{GPa}$, and $14 \mathrm{GPa}$ for S-UHPFRC, S-LFUHPFRC, and PE-UHPFRC, respectively. The tensile response of PE-UHPFRC $\left(^{*}\right)$ under partial restraint condition was almost superimposed on that for the PEUHPFRC specimens under full restraint condition. This indicates that the tensile behavior of the material under imposed shrinkage deformation is independent of the degree of restraint; however, it takes longer for a partial restraint specimen to reach a given stress level than for a full restraint specimen. Furthermore, assuming that the deviation from linearity in the second slope indicates the beginning of the tensile 


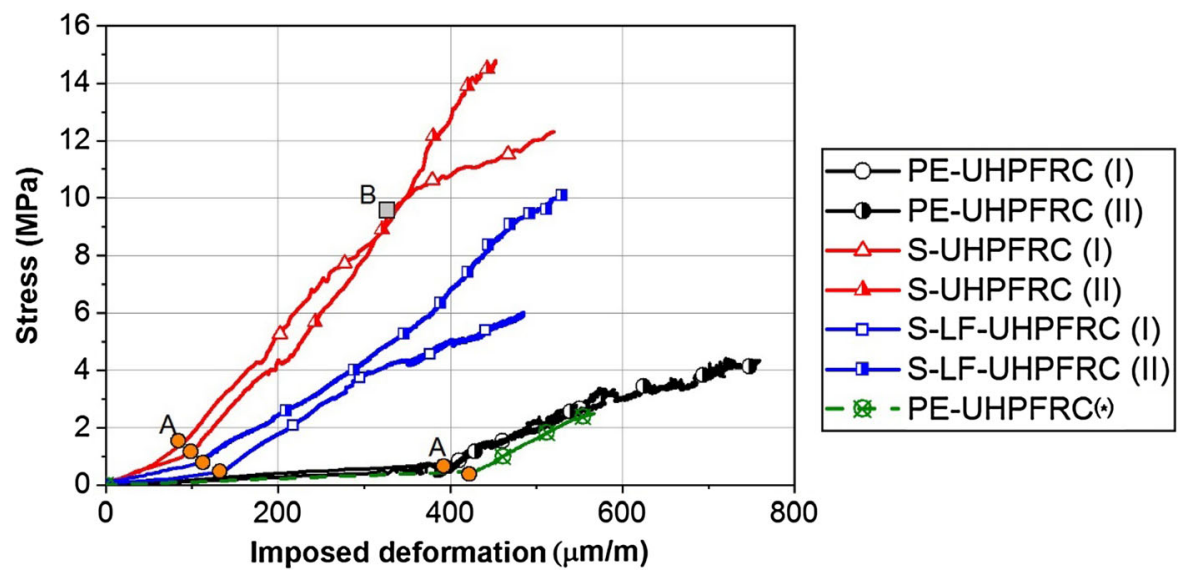

Fig. 8 Tensile response of UHPFRC mixes under imposed shrinkage deformations

Table 4 Age and dynamic elastic modulus of the specimens at point A

\begin{tabular}{lcl}
\hline & Age $(\mathrm{h})$ & Dynamic $E$ modulus $(\mathrm{GPa})$ \\
\hline S-UHPFRC & 25 & 43 \\
S-LF-UHPFRC & 45 & 43 \\
PE-UHPFRC & 150 & 43 \\
\hline
\end{tabular}

hardening domain, it can be noticed that at point $\mathrm{B}$ in Fig. 8, the S-UHPFRC (I) entered the hardening domain when the eigenstresses in this specimen reached the elastic limit at $10 \mathrm{MPa}$ which is lower than 12.3 MPa that stated in Table 2. The differences between these two values can be explained considering the fact that in this case, the specimen was loaded under very low loading rate of imposed shrinkage deformations, and the decrease in the strain rate considerably decreases the elastic limit of the UHPFRC [46]. This highlights the importance of considering eigenstresses in designing UHPFRC layers for rehabilitation.

\section{Conclusions}

- The development of the elastic modulus started earlier in PE-UHPFRC compared with the other two mixes; however, the rate of development was higher for S-UHPFRC. The dynamic elastic modulus reached $45 \mathrm{GPa}$ and $50 \mathrm{GPa}$ for PE-UHPFRC and steel fiber mixes, respectively.
- The autogenous shrinkage was 2-3 times more in PE-UHPFRC compared to that in conventional UHPFRC with steel fibers, in the first days; however, this difference was reduced to $25 \%$ at 28 days. The combined effects of sand amount and steel fibers had a considerable effect on reducing the autogenous shrinkage.

- Replacing cement with limestone filler had a considerable effect on reducing the eigenstresses. Furthermore, using PE fibers instead of steel ones helped in reducing the eigenstresses. PE-UHPFRC showed $70 \%$ and $50 \%$ lower eigenstresses in the two tests under full restraint conditions compared with that in S-UHPFRC and S-LF-UHPFRC, respectively.

- The tensile response of UHPFRC mixes under imposed shrinkage deformations can be considered as bilinear, until the elastic limit. The first part with the smaller slope finished when the dynamic elastic modulus of the material reached $43 \mathrm{GPa}$. The tensile response of the material under shrinkage deformation was independent of the degree of restraint. The eigenstresses in one of the S-UHPFRC specimens passed the elastic limit and entered the hardening domain, which highlights the importance of considering eigenstresses in designing UHPFRC layers for rehabilitation.

Acknowledgements This project is financially supported by the Swiss National Science Foundation (Grant 407040_154063/ 1) through the National Research Program "Energy Turnaround" (NRP 70). The authors would like to gratefully acknowledge Dyneema, Omya, Lafarge-Holcim, and Sika for donating the PE fiber, limestone filler, cement, and 
superplasticizer respectively. The authors also would like to acknowledge Serge Despont and Gilles Guignet, technicians at GIS/EPFL, for their help regarding the preparation and performing the tests.

Funding Open Access funding provided by EPFL Lausanne.

Open Access This article is licensed under a Creative Commons Attribution 4.0 International License, which permits use, sharing, adaptation, distribution and reproduction in any medium or format, as long as you give appropriate credit to the original author(s) and the source, provide a link to the Creative Commons licence, and indicate if changes were made. The images or other third party material in this article are included in the article's Creative Commons licence, unless indicated otherwise in a credit line to the material. If material is not included in the article's Creative Commons licence and your intended use is not permitted by statutory regulation or exceeds the permitted use, you will need to obtain permission directly from the copyright holder. To view a copy of this licence, visit http://creativecommons.org/licenses/by/4.0/.

\section{References}

1. Denarié E, Brühwiler E (2015) Cast-on site UHPFRC for improvement of existing structures-achievements over the last 10 years in practice and research. In: 7th workshop on high performance fiber reinforced cement composites, Stuttgart, Germany

2. Denarié E, Silfwerbrand J, Beushausen H (2011) Structural behaviour, in bonded cement-based material overlays for the repair, the lining or the strengthening of slabs or pavements: state-of-the-art report of the RILEM Technical Committee 193-RLS, pp 81-106

3. Denarié E (2006) SAMARIS D25b-guidance for the use of UHPFRC for rehabilitation of concrete highway structures

4. Kamen A et al (2008) Thermo-mechanical response of UHPFRC at early age-experimental study and numerical simulation. Cem Concr Res 38(6):822-831

5. Habel K (2004) Structural behaviour of elements combining ultra-high performance fibre reinforced concretes (UHPFRC) and reinforced concrete. Doctoral thesis

6. Habel K et al (2006) Autogenous deformations and viscoelasticity of UHPFRC in structures. Part I: experimental results. Mag Concr Res 58(3):135-145

7. Bernard O (2000) Comportement à long terme des éléments de structure formés de bétons d'âges différents. Doctoral thesis

8. Schachinger I et al (2002) Early-age cracking risk and relaxation by restrained autogenous deformation of ultra high performance concrete. In: Proceedings of the 6 international symposium on utilization of high strength/high performance concrete, Leipzig

9. Schiessl P et al (2004) New results on early-age cracking risk of special concrete. Cem Concr Aggreg 26(2):1-9
10. Yoo D-Y et al (2014) Influence of ring size on the restrained shrinkage behavior of ultra high performance fiber reinforced concrete. Mater Struct 47(7):1161-1174

11. Yoo D-Y, Banthia N, Yoon Y-S (2018) Geometrical and boundary condition effects on restrained shrinkage behavior of UHPFRC slabs. KSCE J Civ Eng 22(1):185-195

12. Weimann M, Li V (2003) Hygral behavior of engineered cementitious composites (ECC). Int J Restor Build Monum 9:513-534

13. Hafiz MA, Hajiesmaeili A, Denarié E (2019) Tensile response of low clinker UHPFRC subjected to fully restrained shrinkage. Cem Concr Res 124:105804

14. Hajiesmaeili A, Denarie E (2018) Next generation UHPFRC for sustainable structural applications. ACI Special Publication, vol 326

15. SIA 2052 (2017) Béton fibré ultra-performant (BFUP): Matériaux, dimensionnement et exécution. SNR 592052 ed

16. Kang S-H et al (2019) High-volume use of limestone in ultra-high performance fiber-reinforced concrete for reducing cement content and autogenous shrinkage. Constr Build Mater 213:292-305

17. Bissonnette B, Pigeon M (1995) Tensile creep at early ages of ordinary, silica fume and fiber reinforced concretes. Cem Concr Res 25(5): 1075-1085

18. Hajiesmaeili A (2019) Next generation synthetic fibers UHPFRC for sustainable structural applications. Doctoral thesis, EPFL. https://doi.org/10.5075/epfl-thesis-7362

19. Rossi $\mathrm{P}$ et al (2005) Bending and compressive behaviours of a new cement composite. Cem Concr Res 35(1):27-33

20. Denarié E (2009) ARCHES D06: recommendations for the tailoring of UHPFRC recipes for rehabilitation. In: European project 6th FWP/ARCHES assessment and rehabilitation of central european highway structures, WP 5"Harden Structures to last with UHPFRC". MCS/IIC/ ENAC/EPFL - EU: Lausanne, Brussels

21. Denarié E, Katrin H (2004) SAMARIS D13: report on preliminary studies for the use of HPFRCC for the rehabilitation of road infrastructure components

22. Yoo D-Y, Kim M-J (2019) High energy absorbent ultrahigh-performance concrete with hybrid steel and polyethylene fibers. Constr Build Mater 209:354-363

23. Bjøntegaard $\varnothing$ (1999) Thermal dilation and autogenous deformation as driving forces to self-induced stresses in high performance concrete. Doctoral thesis

24. Kovler K (1994) Testing system for determining the mechanical behaviour of early age concrete under restrained and free uniaxial shrinkage. Mater Struct 27(6):324

25. Charron J-P (2003) Contribution à l'étude du comportement au jeune âge des matériaux cimentaires en conditions de déformations libre et restreinte. Doctoral thesis

26. Kamen A (2007) Comportement au jeune âge et différé d'un BFUP écrouissant sous les effets thermomécaniques. Doctoral thesis

27. Kazemi Kamyab M (2013) Autogenous shrinkage and hydration kinetics of SH-UHPFRC under moderate to low temperature curing conditions. Doctoral thesis

28. Switek AE (2011) Time-dependent response of ultra high performance fibre reinforced concrete (UHPFRC) under low to high tensile stresses. Doctoral thesis

29. Hafiz MA, Denarié E (2017) Experimental study of tensile response of Strain Hardening UHPFRC at early age. In: 
International conference on strain-hardening cement-based composites

30. Kolluru VS, Popovics JS, Shah SP (2000) Determining elastic properties of concrete using vibrational resonance frequencies of standard test cylinders. Cem Concr Aggreg 22(2):81-89

31. Bost P, Regnier M, Horgnies M (2016) Comparison of the accelerating effect of various additions on the early hydration of Portland cement. Constr Build Mater 113:290-296

32. Soroka I, Setter N (1977) The effect of fillers on strength of cement mortars. Cem Concr Res 7(4):449-456

33. Kumar A et al (2013) Simple methods to estimate the influence of limestone fillers on reaction and property evolution in cementitious materials. Cement Concr Compos 42:20-29

34. Bentz DP et al (2012) Fine limestone additions to regulate setting in high volume fly ash mixtures. Cement Concr Compos 34(1):11-17

35. Vance K et al (2013) Hydration and strength development in ternary portland cement blends containing limestone and fly ash or metakaolin. Cement Concr Compos 39:93-103

36. Jensen OM (2005) Autogenous phenomena in cement-based materials. in Doctoral dissertation. Aalborg, København

37. Cheyrezy M, Behloul M (2001) Creep and shrinkage of ultra-high performance concrete. In: Ulm FJ, Bazant ZP, Wittman FH (eds) Creep, shrinkage and durability mechanics of concrete and other quasi-brittle materials. Elsevier, Cambridge

38. Kanellopoulos A, Nicolaides D, Karihaloo BL (2005) Autogenous shrinkage of CARDIFRC $®$. In: CONCREEP7, Nantes, France

39. Meng W, Khayat KH (2018) Effect of hybrid fibers on fresh properties, mechanical properties, and autogenous shrinkage of cost-effective UHPC. J Mater Civ Eng 30(4):4018030

40. Garas VY, Kahn LF, Kurtis KE (2008) Preliminary investigation of the effect of steel fibers on the tensile creep and shrinkage of ultra-high performance concrete. In: The 8th international conference on creep, shrinkage and durability mechanics of concrete and concrete structures

41. Wang S, Li VC (2005) Polyvinyl alcohol fiber reinforced engineered cementitious composites: material design and performances. In: International workshop on HPFRCC structural applications, Hawaii

42. Martinie L, Rossi P, Roussel N (2010) Rheology of fiber reinforced cementitious materials: classification and prediction. Cem Concr Res 40(2):226-234

43. Altoubat SA, Lange DA (2003) A new look at tensile creep of fiber reinforced concrete. ACI Special Publication on Fiber Reinforced Concrete, pp 143-160

44. Bissonnette B, Pigeon M, Vaysburd AM (2007) Tensile creep of concrete: study of its sensitivity to basic parameters. ACI Mater J 104(4):360

45. Garas VY, Kurtis KE, Kahn LF (2012) Creep of UHPC in tension and compression: effect of thermal treatment. Cement Concr Compos 34(4):493-502

46. Hafiz MA, Denarié E (2020) Tensile response of UHPFRC under very low strain rates and low temperatures. Cem Concr Res 133:106067

Publisher's Note Springer Nature remains neutral with regard to jurisdictional claims in published maps and institutional affiliations. 